\title{
PENGETAHUAN DAN DUKUNGAN SUAMI DENGAN KEJADIAN UNMET NEED KELUARGA BERENCANA PADA PASANGAN USIA SUBUR DI WILAYAH PUSKESMAS BIROMARU KABUPATEN SIGI
}

\author{
Sri Yanti Kusika ${ }^{凶}$ \\ Jurusan Kebidanan Poltekkes Kemenkes Palu
}

\begin{tabular}{l}
\hline ARTICLE INFO \\
\hline Article history \\
Submitted : 2018-06-28 \\
Revised : 2018-07-23 \\
Accepted : 2018-07-25 \\
\hline Keywords: \\
Knowledge \\
Husband Support \\
Unmet Need
\end{tabular}

\begin{abstract}
The impact of unmet need is the unwanted pregnancy will end with unsafe abortion and create morbidity and mortality among mother and child. There are many factors and reasons from reproductive age couple as the cause of high unmet need. This is closely related to knowledge and husband support. This study aims to know the association of knowledge, husband support, and unmet need family planning among reproductive age couple. This study is a cross-sectional study and was conducted on September to October 2017. There are 145 respondents involved in this study using proportional stratified random sampling. Chi-square analysis was used for bivariate statistical analysis. Study result shows that there is a significant association of knowledge ( $\mathrm{p}$ value $=0.003$ ), husband support $(\mathrm{p}$-value $=0,001)$ and unmet need family planning. It is suggested to health worker for conducting socialization to give information about the importance to be family planning acceptor, involve husband as a support for wife to be family planning acceptor in order to decrease the number of unmet need and indirectly decrease morbidity and mortality among mother and child.
\end{abstract}

\section{$\triangle$ Corresponding Author:}

\author{
Sri Yanti Kusika \\ Jurusan Kebidanan Poltekkes Kemenkes Palu \\ Telp. 082345553522 \\ Email: sriyanti.kusika@yahoo.com
}

\section{PENDAHULUAN}

Unmet need didefinisikan sebagai kelompok wanita yang sebenarnya sudah tidak ingin mempunyai anak lagi atau ingin menjarangkan kehamilannya sampai dengan 24 bulan namun tidak menggunakan alat kontrasepsi untuk mencegah kehamilannya (BKKBN, 2016). Akibat dari unmet need adalah kehamilan yang tidak diinginkan yang akan berakhir dengan aborsi yang tidak aman (Kennedy, et al, 2013). Berbagai faktor atau alasan pasangan usia subur (PUS) yang menjadi penyebab tingginya unmet need $\mathrm{KB}$. Hal ini berkaitan dengan tingkat pengetahuan dan dukungan suami (Gusti A, 2006).

Secara umum, unmet need KB terdapat pada kelompok pasangan muda, tinggal didaerah pedesaan dan kurang memperoleh pengetahuan tentang alat kontrasepsi. Mereka sangat rentan masuk pada "unwanted pregnancy", untuk melakukan aborsi yang tidak aman (Nofrijal, 2013). Penelitian yang dilakukan oleh Wahab dkk (2014), dengan hasil bahwa ada hubungan pengetahuan dengan kejadian unmet need KB di Kelurahan Siantan Tengah Kecamatan Pontianak Utara $(p=0,000)$. Bahwa tingkat pengetahuan yang baik tentang keluarga berencana akan menentukan pembentukan sikap positif, mengadopsi dan melanjutkan prilaku keluarga berencana.

Ketidaksetujuan suami terhadap pemakaian alat kontrasepsi dengan alasan karena melihat efek samping seperti terganggunya kesehatan istri setelah memakai alat kontrasepsi dan suami menginginkan anak dengan jenis kelamin yang berbeda dari yang telah mereka punya, selain itu suami menginginkan anak dengan jumlah tertentu sebagai pewaris keturunan juga merupakan alasan meningkatnya kejadian unmet need $\mathrm{KB}$ (Sariyati, 2015).

Penelitian yang dilakukan oleh Uljanah dkk (2016), bahwa ada hubungan dukungan suami dengan kejadian unmet need $\mathrm{KB}$ di 
Kecamatan Adiwerna Kabupaten Tegal $((p=$ $0,001)$. Terjadinya unmet need $\mathrm{KB}$ sering kali terjadi ketika suami tidak mendukung terhadap penggunaan alat/cara KB tertentu yang diakibatkan adanya perbedaan fertilitas, kurangnya pemahaman terhadap alat/cara $\mathrm{KB}$, takut akan efek samping, masalah sosial budaya dan berbagai faktor lain (Ismail dkk., 2010).

Data dari BKKBN Kabupaten Sigi Propinsi Sulawesi Tengah Tahun 2016, angka kejadian unmet need KB tertinggi di wilayah Puskesmas Biromaru dengan jumlah unmet need KB sebanyak 10,82\%. Jumlah total Pasangan Usia Subur di wilayah Puskesmas Biromaru adalah 7.751 yang tersebar di 18 Desa (Soko dkk, 2017). Berdasarkan gambaran diatas, maka penelitian ini untuk mengetahui hubungan pengetahuan dan dukungan suami dengan kejadian unmet need $\mathrm{KB}$ pada pasangan usia subur di Wilayah Puskesmas Biromaru Kabupaten Sigi.

\section{METODE PENELITIAN \\ Jenis Penelitian}

Penelitian ini menggunakan desain Cross sectional Study. Desain ini dimaksudkan untuk melihat hubungan pengetahuan dan dukungan suami dengan kejadian unmet need $\mathrm{KB}$ pada pasangan usia subur.

\section{Lokasi dan Waktu Penelitian}

Penelitian ini telah dilaksanakan di Wilayah Puskesmas Biromaru pada Bulan September sampai dengan Bulan Oktober 2017.

\section{Populasi dan Sampel}

Populasi dalam penelitian ini adalah seluruh pasangan usia subur yang ada di Wilayah Puskesmas Biromaru pada tahun 2016 berjumlah sebesar 7.751 PUS. Besar sampel ditentukan dengan menggunakan rumus Lemeshow (1997) adalah 145.

Penarikan sampel dari populasi penelitian dilakukan dengan cara proportional stratified random sampling. Besar sampel yang diperoleh kemudian diproporsikan untuk menentukan pengambilan sampel dari setiap desa yang ada di wilayah Puskesmas Biromaru.

\section{Pengumpulan Data}

Data diperoleh langsung dari responden dengan wawancara secara terpimpin dan terarah, menggunakan kuesioner yang telah diuji validitas dan reliabilitasnya.

\section{Pengolahan dan Analisis Data}

Data diolah melalui proses editing, coding, entry data. Data dianalisis secara deskriptif dengan distribusi frekuensi dan uji hipotesis menggunakan uji chi-square.

\section{HASIL PENELITIAN}

Analisis Deskriptif

Tabel 1. menunjukkan responden yang memiliki pengetahuan kurang tentang KB lebih tinggi dibandingkan dengan responden yang memiliki pengetahuan baik tentang KB. Terdapat sebagian besar responden tidak mendapat dukungan suami untuk menggunakan kontrasepsi dibandingkan dengan responden yang mendapat dukungan suami untuk menggunakan kontrasepsi. Sebagian besar kejadian Unmet Need $K B$ terjadi pada PUS.

Tabel 1. Distribusi Responden Berdasarkan Pengetahuan tentang KB, Dukungan Suami, Kejadian Unmet Need KB di wilayah Puskesmas Biromaru Kabupaten Sigi

\begin{tabular}{lcc}
\hline \multicolumn{1}{c}{ Variabel Penelitian } & Frekuensi & Prosentase \\
\hline Pengetahuan & 79 & \\
$\quad$ Kurang & 66 & 54,5 \\
$\quad$ Baik & & 46,5 \\
Dukungan Suami & 82 & 56,6 \\
$\quad$ Tidak & 63 & 43,4 \\
$\quad$ Ya & & 57,2 \\
Kejadian Unmet Need KB & 83 & 42,8 \\
$\quad$ Ya & 62 & $\mathbf{1 0 0}$ \\
$\quad$ Tidak & $\mathbf{1 4 5}$ & \\
\hline Total & & \\
\hline
\end{tabular}


Pada Tabel 2. menunjukkan kejadian unmet need KB lebih besar pada PUS dengan pengetahuan kurang $(68,4 \%)$ dibandingkan pada PUS dengan pengetahuan baik $(43,9 \%)$. Hasil uji Chi-Square memperlihatkan hasil yang bermakna dengan nilai $p=0,003$ $(p<0,05)$, sehingga disimpulkan pengetahuan berhubungan dengan kejadian unmet need KB. Berdasarkan tabel itu pula kejadian unmet need KB lebih besar pada PUS dengan dukungan suami yang kurang $(69,5 \%)$ dibandingkan pada PUS yang mendapat dukungan suami dalam mengunakan alat kontrasepsi (41,3\%). Hasil uji Chi-Square memperlihatkan hasil yang bermakna $p=0,001 \quad(p<0,05)$, sehingga disimpulkan dukungan suami berhubungan dengan kejadian unmet need $\mathrm{KB}$.

Tabel 2. Hubungan Pengetahuan dan Dukungan Suami dengan Kejadian Unmet Need KB pada PUS di wilayah Puskesmas Biromaru Kabupaten Sigi

\begin{tabular}{|c|c|c|c|c|c|c|c|}
\hline \multirow{3}{*}{ Variabel } & \multicolumn{4}{|c|}{ Unmet Need KB } & \multirow{2}{*}{\multicolumn{2}{|c|}{ Jumlah }} & \multirow{3}{*}{ p value } \\
\hline & \multicolumn{2}{|c|}{$\mathbf{Y a}$} & \multicolumn{2}{|c|}{ Tidak } & & & \\
\hline & $\bar{n}$ & $\%$ & $\mathbf{n}$ & $\%$ & $\bar{n}$ & $\%$ & \\
\hline \multicolumn{8}{|l|}{ Pengetahuan } \\
\hline Kurang & 54 & 68,4 & 25 & 25,3 & 79 & 100 & \multirow{2}{*}{0,003} \\
\hline Baik & 29 & 43,9 & 37 & 49,2 & 66 & 100 & \\
\hline \multicolumn{8}{|c|}{ Dukungan Suami } \\
\hline Tidak & 57 & 69,5 & 25 & 30,5 & 82 & 100 & \multirow{2}{*}{0,001} \\
\hline $\mathrm{Ya}$ & 26 & 41,3 & 37 & 58,7 & 63 & 100 & \\
\hline Jumlah & 83 & 57,2 & 62 & 42,8 & 145 & 100 & \\
\hline
\end{tabular}

\section{PEMBAHASAN}

Menurut Notoatmodjo (2003), pengetahuan merupakan hasil dari tahu dan ini terjadi setelah seseorang melakukan penginderaan terhadap objek tertentu. Penginderaan terjadi melalui panca indera manusia, yaitu indera penglihatan, pendengaran, penciuman, rasa dan raba.

Adanya hubungan antara pengetahuan dengan terjadinya unmet need $\mathrm{KB}$ terjadi karena pengetahuan sebagai tahap awal proses pembentukan suatu perilaku yang terdiri dari pengetahuan, persuasi, keputusan dan konfirmasi. Dengan pengetahuan yang baik tentang keluarga berencana akan menentukan pembentukan sikap positif, mengadopsi dan melanjutkan prilaku keluarga berencana (Wahab dkk, 2014).

Tabel 2. menunjukkan kejadian unmet need KB lebih besar pada PUS dengan pengetahuan kurang $(68,4 \%)$ dibandingkan pada PUS dengan pengetahuan baik $(43,9 \%)$. Pengetahuan responden yang kurang tentang $\mathrm{KB}$, salah satunya dapat menjadi penyebab tingginya kejadian unmet need KB. Hasil uji Chi-Square memperlihatkan hasil yang bermakna $(p=0,003)$ dimana nilai $p<0,05$, sehingga disimpulkan bahwa pengetahuan berhubungan dengan kejadian unmet need KB.

Pengetahuan tentang program KB pada PUS sangat perlu disebar luaskan, sehingga masyarakat dapat mengetahui dampak atau risiko akibat tidak menunda usia perkawinan atau menunda kehamilan hingga betul-betul siap untuk menjadi ibu, atau mengatur jarak kehamilan sehingga setiap anak dapat terpenuhi kebutuhan kasih sayang dari orang tuanya ataupun membatasi jumlah anak pada usia yang berisiko bila terjadi kehamilan atau persalinan. Bila masyarakat mengetahui akan pentingnya menjadi akseptor KB maka laju pertambahan penduduk akan dapat ditekan sehingga setiap keluarga akan dapat menikmati jumlah anak yang kecil dan berkualitas.

Pendidikan kesehatan dalam hal ini adalah pengetahuan tentang manfaat pengunaan alat kontrasepsi merupakan faktor penting untuk mengurangi kejadian unmet need KB (Adebowale, 2014). Penelitian yang dilakukan oleh Benard (2014) di Kenya, didapatkan hasil bahwa pengetahuan tentang keluarga berencana berhubungan dengan kejadian unmet need $\mathrm{KB}$ dengan nilai $p=0,001$. Demikian pula penelitian yang 
dilakukan oleh Assefa dan Haddis (2011) di Ethopia, dengan hasil bahwa pengetahuan tentang metode keluarga berencana memiliki pengaruh yang signifikan terhadap kejadian unmet need KB.

Dukungan suami merupakan salah satu variabel sosial budaya yang sangat berpengaruh terhadap pemakaian alat kontrasepsi bagi seorang istri dalam suatu keluarga. Budaya patrilineal yang menjadikan pria sebagai kepala keluarga yang masih banyak dianut sebagian besar pola keluarga di Indonesia, sehingga menjadikan preferensi suami terhadap fertilisasi dan pandangan serta pengetahuannya terhadap program KB akan sangat berpengaruh terhadap keputusan dalam keluarga untuk menggunakan alat atau metode keluarga berencana tertentu. Sehingga di dalam beberapa penelitian, variabel penolakan atau persetujuan dari suami terbukti berpengaruh terhadap kejadian unmet need dalam rumah tangga (Ismail dkk, 2010).

Tabel 2. menunjukkan kejadian unmet need KB lebih besar pada PUS dengan dukungan suami yang kurang (69,5\%) dibandingkan pada PUS yang mendapat dukungan suami dalam mengunakan alat kontrasepsi (41,3\%). Bila dukungan suami kurang kepada isteri dalam menggunakan alat kontrasepsi maka dapat menjadi penyebab tingginya kejadian unmet need KB. Hasil uji Chi-Square memperlihatkan hasil yang bermakna $(p=0,001)$ dimana nilai $p<0,05$, sehingga disimpulkan bahwa dukungan suami berhubungan dengan kejadian unmet need KB.

Adapun bentuk dukungan suami dalam penelitian ini berupa suami mengantar ke tempat pelayanan $\mathrm{KB}$, pemilihan jenis kontrasepsi didiskusikan bersama dan suami mengingatkan waktu kontrol, suntik, atau minum pil sesuai alat kontrasepsi yang digunakan. Kejadian unmet need $\mathrm{KB}$ seringkali terjadi ketika suami tidak mendukung terhadap penggunaan alat atau metode KB tertentu yang diakibatkan adanya perbedaan fertilitas, kurangnya pemahaman alat atau metode kontrasepsi, takut akan efek samping, masalah sosial budaya, dan berbagai faktor lainnya. Pembicaraan antara suami dan istri mengenai $\mathrm{KB}$ tidak selalu menjadi persyaratan dalam pemakaian $\mathrm{KB}$, namun tidak adanya diskusi tersebut dapat menjadi halangan terhadap pemakaian KB (Ismail dkk, 2010).

Penelitian yang dilakukan di kota Dangila, Ethiopia oleh Genet et al (2015) didapatkan hasil bahwa wanita yang pasangannya memiliki sikap tidak mendukung untuk penggunaan keluarga berencana berisiko 3 kali lebih besar terhadap kejadian unmet need KB. Ajong et al (2016) dalam penelitiannya didapatkan hasil bahwa persetujuan suami dalam penggunaan kontrasepsi berhubungan dengan kejadian unmet need $\mathrm{KB}(p=0,023)$.

Bentuk dukungan yang kurang berupa larangan atau ketidaksetujuan suami terhadap pemakaian alat kontrasepsi disebabkan oleh adanya beberapa alasan yaitu suami melihat adanya efek samping akibat pemakaian alat kontrasepsi yang dirasakan istri sehingga mengganggu kesehatan istri, suami yang menginginkan anak dengan jenis kelamin yang berbeda dan menginginkan anak dengan jumlah tertentu sebagai pewaris keturunan dan membantu mencari nafkah dalam keluarga (Sariyati, 2015). Penelitian yang dilakukan oleh Samandari (2010) di Kamboja menyimpulkan bahwa untuk mempromosikan penggunaan kontrasepsi dalam program keluarga berencana harus fokus pada peningkatan persetujuan laki-laki. Menurut Genet et al, (2015), upaya konseling dan keterlibatan pasangan dalam menentukkan penggunaan alat kontrasepsi juga sangat mendukung upaya untuk mengurangi kejadian unmet need $\mathrm{KB}$.

\section{KESIMPULAN DAN SARAN}

Pengetahuan dan dukungan suami berhubungan dengan kejadian unmet need $\mathrm{KB}$ pada PUS.

Bagi petugas kesehatan diharapkan dapat melakukan sosialisasi berupa informasi tentang pentingnya menjadi akseptor KB. Dengan hal tersebut diharapkan angka kejadian unmet need $\mathrm{KB}$ menurun dan secara tidak langsung dapat menurunkan angka morbiditas dan mortalitas pada ibu dan bayi.

Dukungan suami dalam penggunaan alat kontarsepsi sangat erat hubungannya dengan kejadian unmet need KB. Diharapkan komunikasi yang efektif dilakukan bukan hanya pada ibu sebagai calon akseptor tetapi juga dengan melibatkan suami dalam penentuan penggunaan alat kontrasepsi yang 
tepat bagi istrinya sekaligus sebagai bentuk dukungan pada istri untuk menjadi akseptor KB.

\section{DAFTAR PUSTAKA}

Adebowale AS. Palamuleni EM. (2014). Determinants of Unmet Need for Modern Contraception and Reasons for Non-use among Married Women in Rural Areas of Burkina Faso. African Population Studies. Vol. 28. No. 1.

Ajong BA. Njotang NP. Yakum NM. (2016). Determinants of Unmet Need for Family Planning Among Women in Urban Cameroon: a Cross Sectional Survey in the Biyem-Assi Health District, Yaounde. BMC Women's Health. https: //bmcwomenshealth. biomedcentral. com/articles/.

Benard N. (2014). Determinants of Unmet Need for Family Planning among Women in Rural Kenya. African Population Studies. Vol 28, No.2.

BKKBN. (2016) Laporan Kinerja Instansi Pemerintah 2015. Badan Kependudukan dan Keluarga Berencana Nasional.

Genet E. Abeje G. Ejigu T. (2015). Determinants of unmet need for family planning among currently married women in Dangila town administration, Awi Zone, Amhara regional state; a cross sectional study. Reproductive Health Journal. Vol. 12, No. 42.

Gusti A. (2006). Faktor-Faktor Eksternal yang Berpengaruh Terhadap Prevalensi Unmet Need di Provinsi Bali, Jurnal Penelitian Kesehatan Suara Forikes, Vol. 11, No. 2.

Ismail \& Fitria D. (2010). Faktor-Faktor yang Berhubungan dengan Terjadinya Unmet Need KB pada PUS di Kelurahan Sempaja Selatan, Kecamatan Samarinda Utara. Skripsi (Tidak Diterbitkan). Fakultas Kesehatan Masyarakat Universitas Mulawarman.
Kennedy E. Mackesy BS. Subramaniam S. (2013). The Case for Investing in Family Planning in the Pacific : Costs and Benefits of Reducing Unmet Need for Contraception in Vanuatu and the Solomon Islands. Reproductive Health Journal. http://www. reproductivehealth-journal.com/content/10/1/30.

Lemeshow S. David W. (1997). Besaran Sampel Dalam Penelitian Kesehatan. Gadjah Mada University Press, Yogyakarta.

Nofrijal. (2013). The International Of Training And Collaboration: Unmet Need, Artikel, http://itpbkkbn. blogspot.co.id/2013/06/unmetneed.html

Notoatmodjo S. (2003). Pendidikan dan Perilaku Kesehatan, Rineka Cipta, Jakarta

Samandari. (2010). The Role of Social Support and Parity On ContraceptiveUse in Cambodia, International Perspectives on Sexual and Reproductive Health, Artikel Vol.36, No. 3.

Sariyati. (2015). Faktor yang Berhubungan dengan Terjadinya Unmet Need KB pada Pasangan Usia Subur (PUS) di Kota Yogyakarta. Jurnal Ners dan Kebidanan Indonesia. Vol. 3, No. 3.

Soko M. Hardani H. Maryani. (2017). Profil Kesehatan Puskesmas Biromaru Tahun 2016.

Uljanah K. Winarni. Mawarni. (2016). Hubungan Faktor Risiko Kejadian Unmet Need KB Di Kecamatan Adiwerna, Kabupaten Tegal. Jurnal Kesehatan Masyarakat. Vol. 4, No. 4.

Wahab R. Agus F. Mitra. (2014). Hubungan Antara Faktor Pengetahuan Istri dan Dukungan Suami terhadap Kejadian Unmet Need KB pada Pasangan Usia Subur Di Kelurahan Siantan Tengah Kecamatan Pontianak Utara, Skripsi (Tidak Diterbitkan). Fakultas Kedokteran Universitas Tanjungpura. 